\title{
Research on Neural Network Intimal Control of Wind-PV Hybrid Power System
}

\author{
Guangjun $\mathrm{Ma}^{1, \mathrm{a}}$, Bingbing $\mathrm{Wu}^{2, \mathrm{~b}^{*}}$ \\ ${ }^{1}$ Liaoning Equipment Manufacturing Professional Technology College,Shenyang, China \\ ${ }^{2}$ Liaoning Equipment Manufacturing Professional Technology College,Shenyang, China \\ a1015159762@qq.com, b405950341@qq.com
}

\begin{abstract}
Keywords: wind-solar complementation; power generation; neural network control
Abstract. This paper models and analyzes the photovoltaic power generation and wind power generation in the wind-solar hybrid generation system. A neural network inner membrane controller based on wind-solar hybrid power generation system is designed. The closed-loop control system is used to make the output power constant. The simulation results show that the neural network inner membrane controller is used to control the wind-solar hybrid power generation system. The operation is stable and reliable, and the effectiveness of the neural network inner membrane control system for wind-solar hybrid generation is verified.
\end{abstract}

With the traditional energy consumption and environmental issues have become increasingly prominent. Solar energy and wind energy are the most mature, most large-scale and industrialized clean energy currently used in the world, and they are valued by all countries in the world. As photovoltaic power generation is affected by factors such as light and temperature, the output power of photovoltaic cells changes continuously with the environmental changes [1]. Wind-solar hybrid power generation system can make full use of the complementarity of wind energy and solar energy in time and season, and obtain a constant power output. In the same power supply, the configuration capacity of energy storage equipment can be reduced [2-3].

\section{The composition and operation of wind-solar hybrid power generation system}

Wind-solar hybrid power generation system (physical device) is shown in Figure 1. Its block diagram is shown in Figure 2. The system consists of wind generators, fan chargers, solar panels, solar chargers, batteries, controllers and loads.

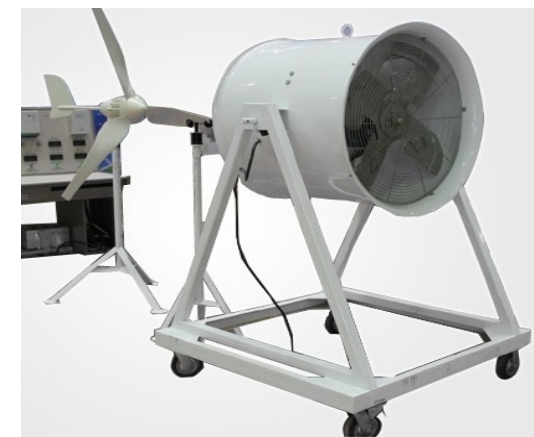

Fig.1 Wind-solar hybrid power generation system (physical device)

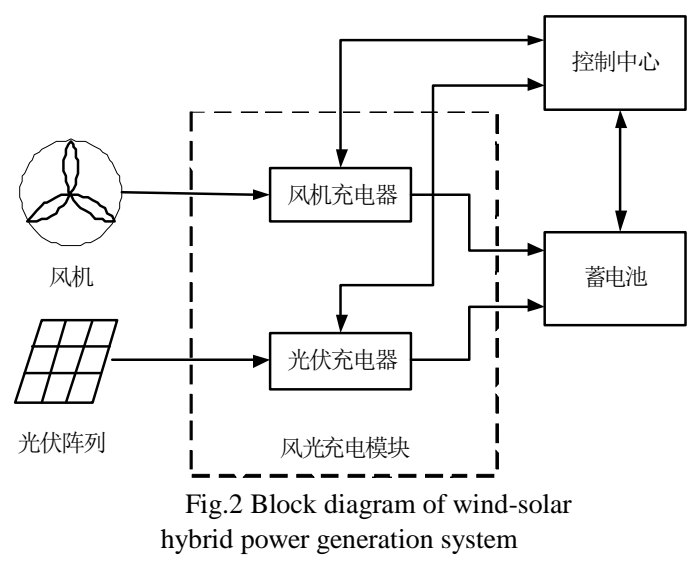

hybrid power generation system 


\section{Modeling of wind-solar hybrid power generation system}

\section{Photovoltaic Power System Model}

In engineering applications, several photovoltaic cells are connected in series or in parallel to form a battery group. Therefore, the output characteristic curve equation of the photovoltaic power generation system is [4-6]

The formula (1), I is the output current of the photovoltaic cell; $\mathrm{np}$ is the number of photovoltaic cells in parallel; ns is the number of photovoltaic cells in series; Iph is photocurrent; Io is the reverse saturation current of the internal PN junction of the photovoltaic cell; $q$ is the charge constant; $U$ is Photovoltaic cell output voltage; Rs is the series equivalent resistance of the photovoltaic cell; $n$ is the PN section characteristic factor; $\mathrm{k}$ is the Boolean Zimmermann constant; $\mathrm{T}$ is the photovoltaic cell temperature.

$$
I=n_{p} I_{p h}-n_{p} I_{0}\left\{\exp \left[\frac{q\left(\mathrm{U}+I R_{s}\right.}{n k T n_{s}}\right]-1\right\}
$$

\section{Wind Power Generation Model}

According to aerodynamics, the fan captures mechanical power and torque expressions[7-8]

$$
\begin{gathered}
P_{m}=\frac{1}{2} \rho \pi R^{2} C_{p}(\lambda, \beta) V^{3} \\
T_{m}=\frac{1}{2} \rho \pi R^{3} C_{p}(\lambda, \beta) V^{2} / \lambda \\
\lambda=R \omega_{r} / V
\end{gathered}
$$

In the formula, $\rho$ is the air density; $\pi$ is the pi constant; $\mathrm{R}$ is the fan blade radius; $\mathrm{Cp}$ the wind energy utilization coefficient, $\lambda$ is the tip speed ratio, $\beta$ is the pitch angle of the blade; $V$ is the wind speed of the wind turbine, $\omega r$ is the fan speed.

\section{Wind-solar hybrid power generation system neural network inner membrane control}

As shown in Fig. 3, the principle of the neural network internal model control, that is, the control system integrates the principles of the dual network structure direct inverse control and the neural network internal model control. In the figure, $\mathrm{NN1}$ is the system identification neural network, and NN2 is the inverse model of the system. NN1 and NN2 have the same neural network structure. That is, NN1 and NN2 have the same number of input, output, and hidden layer nodes, and use e2=u-v as the training signal. After the neural network is trained, its control effect is as shown in FIG. As shown in Figure 4, it can be seen from the figure that the control effect is indeed very good [9-11].

Fig. 4 is the neural network control model of the wind-solar hybrid power generation system after neural network training [12]. The control target of the system is that the output power is as close as possible to the reference value Vac. Where $W$ is the wind speed and the unit is $\mathrm{m} / \mathrm{s}$. $L$ is the illuminance and the unit is watts/square meter. $V_{0}$ is the power set by wind-solar hybrid power generation system, and the unit is Watt. $V a$ is the output power of the wind-solar hybrid power generation system in watts.

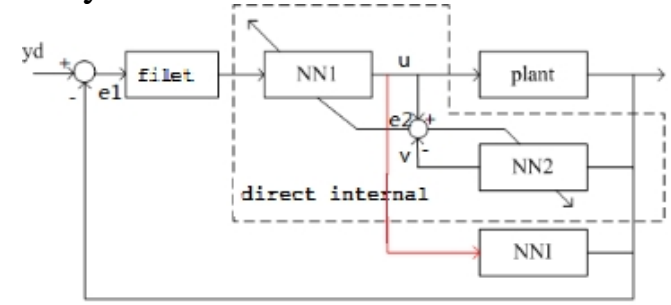

Fig. 3 Schematic diagram of neural network internal model control

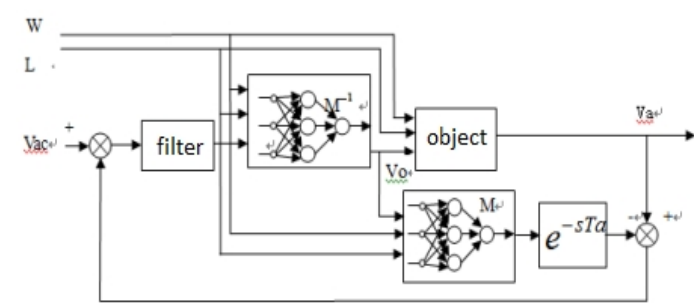

Fig.4 Neural network control model of wind-solar hybrid power generation system 
Due to the uncertainties of wind energy and solar energy, the magnitude of voltage change in wind-solar hybrid power generation systems is large, and in particular, the change of wind turbine speed is too large, which directly affects the stability of the system. The system uses a neural network controller to achieve intelligent control.

\section{Simulation results}

In order to verify the neural network control strategy, according to the control model, the system's Matlab/Simulink simulation model was established and verified. The main parameters of the fan simulation model are shown in Table 1. The main parameters of the photovoltaic cell simulation model are shown in Table 2.

Table 1 The main parameters of the fan simulation model

\begin{tabular}{cccc}
\hline No. & Parameter & Unit & Value \\
\hline 1 & fan impeller diameter & $\mathrm{m}$ & 3 \\
2 & Rated wind speed & $\mathrm{m} / \mathrm{s}$ & 10 \\
3 & working wind speed & $\mathrm{m} / \mathrm{s}$ & $3.5 \sim 15$ \\
4 & Generator rated & Watts & 500 \\
& power & rev/min & 400 \\
5 & Generator rated & speed & \\
\end{tabular}

\begin{tabular}{cccc} 
Table 2 The main parameters of the photovoltaic cell simulation \\
\hline No. & Parameter & Unit & Value \\
\hline 1 & open circuit & voltage & 24 \\
2 & Peak Power & Watts & 800 \\
3 & peak voltage & volts & 17.5 \\
4 & Peak Current & Ampere & 5 \\
5 & $\begin{array}{c}\text { Standard light } \\
\text { intensity }\end{array}$ & $\mathrm{W} / / \mathrm{m}^{2}$ & 1000 \\
\hline
\end{tabular}

In simulation experiments, the changes in the external conditions were simulated by individually or simultaneously adjusting the light intensity and wind speed values, and the changes in the output power of the wind-solar hybrid power generation system controlled by the neural network were detected, and the characteristic curves were plotted. The resulting simulation results are shown in Figure 5-6.Figure 5 shows that when the light intensity alone is adjusted from $600 \mathrm{~W} / \mathrm{m}^{2}$ to 1000 $\mathrm{W} / \mathrm{m}^{2}$, the output power of the system increases synchronously with the increase of the light intensity, which indicates that the photovoltaic battery pack is working. In the maximum power state.
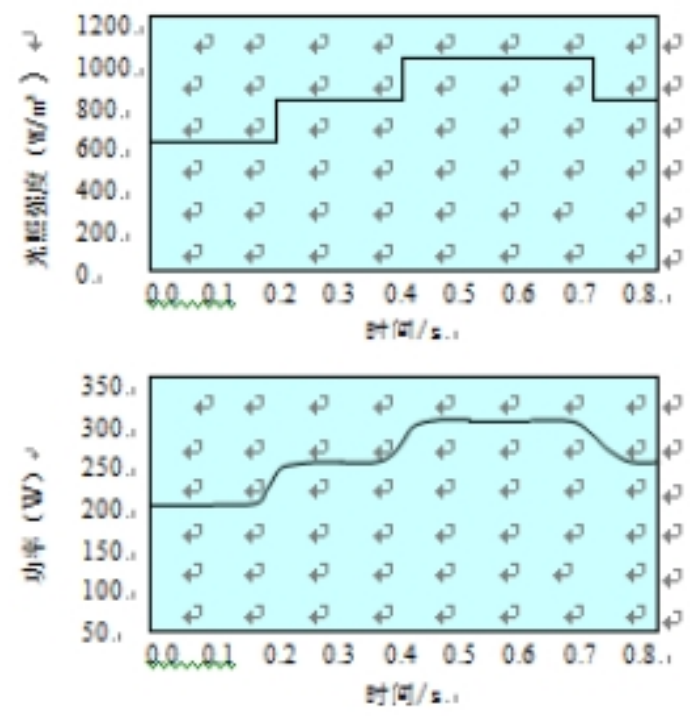

Fig. 5 Relationship between light intensity and output power of photovoltaic cells
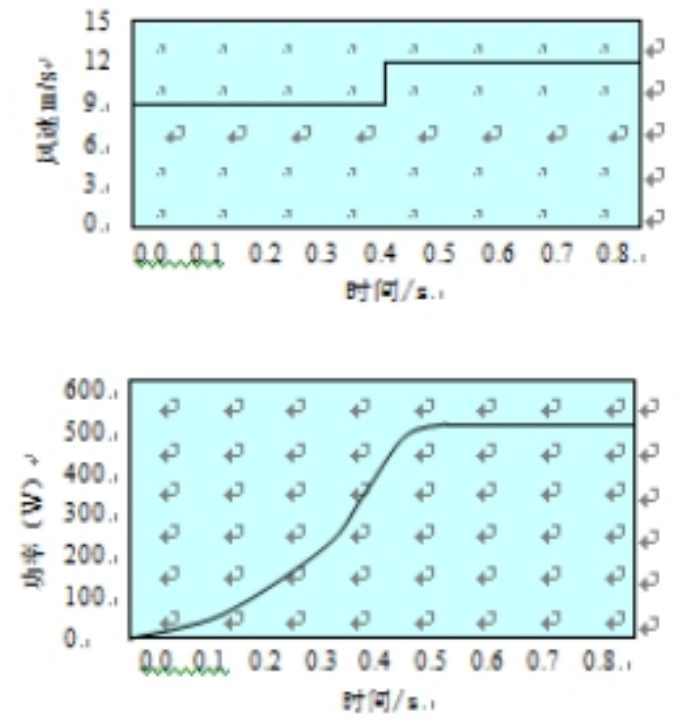

Fig. 6 Wind power output at the same time

It can be seen from Fig. 6 that when the cut-in wind speed alone is increased from $9 \mathrm{~m} / \mathrm{s}$ to $12 \mathrm{~m} / \mathrm{s}$, the output power of the system changes synchronously with the increase of the cut-in wind speed, which means that the fan is operating at the maximum power.

The actual working conditions of the power generation system are often wind, light channels work at the same time or work independently on a single channel. In the experiment, considering that 
the wind and light are in the state of simultaneous power generation, that is, the adjustment light intensity variation range is between $600 \mathrm{~W} / \mathrm{m}^{2}$ and $1000 \mathrm{~W} / \mathrm{m} 2$, and the adjustment cut-in wind speed change range is between $9 \mathrm{~m} / \mathrm{s}$ and $12 \mathrm{~m} / \mathrm{s}$, and is randomly given Constant energy input controls the system output so that it approaches the setpoint. The effect is shown in Figure6.

In summary, the photovoltaic cells in the system work as the power generation module in the maximum power tracking state to maximize the use of light energy. The wind power generation module sends out electric energy according to the load and the required power of the storage battery, ensuring the balance of the energy of the entire system and embodying a good real-time tracking characteristic. The simulation results show that the output power of the scenery can adjust the output power in time according to the changes of the external conditions. At the same time, the storage battery has a certain role of storage and compensation of energy, reflecting the reliability of wind and solar power generation, and the neural network control effect of the wind-solar hybrid power generation system is accurate.

\section{Conclusion}

This paper uses neural network control strategy to control the output voltage of the wind-solar hybrid power generation system to meet the load requirements and improve the reliability of the system. The system can reasonably dispatch the system energy supply, embody the good characteristics of wind and solar complementation, achieve energy balance, and have good control performance. The simulation results show that the wind-solar hybrid power generation system studied in this paper can still achieve constant power output under the conditions of simultaneous generation of wind energy and solar energy, alternate generation, and load disturbance. The system has high dynamic performance and stability.

\section{References}

[1] Yang Fei. Wind-solar hybrid intelligent controller research [D]. Journal of Xinjiang University, 2013, 1-1

[2] Chen Songli, Tian De, Sun Yunfeng et al. Matching of household wind and solar power generation systems [J]. Journal of Jilin University, 2012, 42( 4): 882-886

[3] Yang Jinxiao, Zhu Lin. Based on MATLAB/Simulink photovoltaic cell model research [J]. Modern Electronics Technology, 2011, 34( 24): 192-198

[4] Zhang Mingrui et al. Modeling and Simulation of a Grid-Connected Wind-Solar Hybrid Power Generation System [J]. Grid and Clean Energy, 2014, 22( 26): 248- 252

[5] Liu Xingjie, The equivalent method of photovoltaic power generation system model based on electrical external characteristics [J]. Electrotechnical Technology, 2014, (10).

[6] Sun Hao, et al. General-purpose electromechanical transient model of grid-connected photovoltaic power generation system and its comparison with electromagnetic transient model, power system protection and control, 2014, (3)

[7] Huang Yiyi; An Xiaoyu et al. Multi-mode energy control and management of off-grid wind-solar hybrid power generation system [J], Journal of Northwestern Polytechnical University, 2013, 27(4)

[8] Lu Meiling, Zhang Geng. Optimized economic efficiency scheduling model of home photovoltaic power generation system for energy internet $[\mathrm{J}]$, Journal of Electric Power Systems and Automation, 2016, (1)

[9] Huang Jiaming. Development Status and Prospect of Wind Power Generation [J], Applied Energy Technology, 2015, (4)

[10] Junjun Chen. Study on Reheat Steam Temperature Control System of Supercritical Unit Based on Internal Model Principle [J], 2016 56-63

[11]Zhu Jianmin, Shen Yu. Experimental Research on Position Control of Cue System Based on RBF Neural Network Control [J], 2017(12) 
[12] MA Guang Jun, Wu Shuo. Neural networks control of the Ni- MH power battery positive mill thickness [J]. "Applied Mechanics and Materials" 2013.9, 1855-1858 (411-414) 